\section{Investigation on the Profile of Phenolic Acids and Flavonoids with Antioxidant Capacity in Florida Highbush (Vaccinium corymbosum L.) and Rabbiteye (Vaccinium virgatum) Blueberries}

\author{
Mei Song ${ }^{1,3}$, James W. Olmstead ${ }^{2}$, Russell L. Rouseff ${ }^{1,4}$ and Elizabeth Tomasino ${ }^{3^{*}}$ \\ ${ }^{1}$ Citrus Research and Education Center, University of Florida, 700 Experiment Station Road, Lake Alfred, Florida 33850, United States \\ ${ }^{2}$ Department of Horticultural Sciences, University of Florida, Gainesville, Florida 3261 United States \\ ${ }^{3}$ Department of Food Science \& Technology, Oregon State University, 100 Wiegand Hall, Corvallis, Oregon 9733 United States \\ ${ }^{4}$ Citrus Research Institute, CAAS, National Citrus Engineering Research Center, Southwest University, Chongqing, China
}

"Corresponding author: Elizabeth Tomasino, Department of Food Science \& Technology, Oregon State University, 100 Wiegand Hall, Corvallis, Oregon, USA 9733 Tel: 541-737-4866; Fax: 541-737-1877; E-mail: elizabeth.tomasino@oregonstate.edu

Received date: Nov 20, 2015; Accepted date: Dec 2015; Published date: Dec 8, 2015

Copyright: @2015 Tomasino E, et al. This is an open-access article distributed under the terms of the Creative Commons Attribution License, which permits unrestricted use, distribution, and reproduction in any medium, provided the original author and source are credited.

\begin{abstract}
It is well documented that blueberry phenolic compositions, such as phenolic acids and flavonoids differ based on species and cultivars. However, phenolic compositions in Florida blueberries have been little explored. Information on Florida blueberries are of interest as they are harvested earlier than other areas of the United States, which may result in compositional differences due to shorter daylight hours and cooler temperatures. Samples were harvested from University of Florida grower-cooperator farm near Gainesville, FL. After liquid-liquid extraction and C-18 SPE cartridge purification, concentrations of phenolic acids and flavonoids of twenty two blueberry cultivars (20 highbush and 2 rabbiteye) were measured using HPLC. Five phenolic acids (gallic acid, protocatechuic acid, chlorogenic acid, caffeic acid and ferulic acid), two flavan-3-ols (catechin and epicatechin) and five flavonols (quercetin-3-galactoside or quercetin-3-glucoside, quercetin-3-arabinoside, myricetin, quercetin and kaempferol) were identified and quantified. Chlorogenic acid was the major component in highbush blueberries. Flavonoid and phenolic acid composition were profoundly different among Florida blueberries and these differences have not been previously reported. The first two components of PCA explained $95 \%$ of the variation totally; it showed clear differentiation of blueberry cultivars based on phenolic composition. The majority of the variation between the cultivars was due to variation in quercetin-3-galactoside or glucoside, quercetin-3-arabinoside and chlorogenic acid, which are most likely due to genetic and maturity differences. Complete-linkage clustering analysis displayed five significantly different $(p<0.05)$ clusters of blueberries, which were in agreement with PCA results, although some small differences were noted. Furthermore, Florida blueberries can be differentiated based on phenolic composition between highbush and rabbiteye species and varieties. Low flavanol content in rabbiteye blueberries may be related to maturity as these compounds typically decrease as berries ripen. Although the concentrations for phenolic compositions were lower than found in other reports, Florida blueberries contained a greater range of phenolic compounds. This information is valuable for blueberry breeding programs and growers for development of higher phenolic composition cultivar.
\end{abstract}

Keywords: Blueberry; Cultivars; Phenolic acid; Flavonoid; HPLC; PCA; Complete-linkage clustering

\section{Introduction}

Florida blueberries are a major source of spring or early summer blueberries, currently ranking fifth for commercial acreage in the U.S. market [1]. It was reported that the acreage and production has increased by $73 \%$ and $132 \%$ between 2007 and 2012 [1]. The twenty two cultivars investigated in this study are already established including major cultivars 'Star,' 'Emerald,' 'Jewel', 'Springhigh' and 'Primadonna'; as well as newly released in 2009, 'Meadowlark,' 'Flicker', 'Bobolink' and 'Raven'. These blueberries are all low-chill cultivars which only require around 150-800 chill hours below 45 degrees to set fruits. Many of these blueberries are patented cultivars released by the University of Florida and the phenolic content has yet to be determined, and can provide important information to blueberry breeders and producers for high value-added and phenolic content cultivar development. Phenolic compounds include phenolic acids and flavonoids, which are abundant in vegetables, fruits and other food products. These compounds confer unique taste, flavor, and healthpromoting properties [2-5]. Phenolic acids and flavonoids are important antioxidant compounds performing a series of functions directly or indirectly with human low-density lipoproteins [6], can enhance postprandial serum antioxidant status and may reduce many chronic degenerative diseases [7]. Due to these health benefits there is an increasing interest in determining the antioxidant activities of these compounds [6,8-13]. Phenolic acids are secondary metabolites found in fruits [14-17], beans [18], and other vegetables [19,20]. These acids are associated with sour, bitter, and astringent flavors found in vegetable proteins [21]. Hydroxycinnamic acids such as chlorogenic acid and caffeic acid are a specific class of phenolic acids that have been found to play a role in vegetable maturation and plant defense, as well as influence fruit flavor quality [22]. Flavonoids are also secondary metabolites of plants with polyphenolic structure that are synthesized from phenylalanine through the shikimic acid pathway [23]. Among flavonoids, flavan-3-ols which are the building blocks for proanthocyanidins and anthocyanidins, are of interest in this study. Flavan-3-ols are most prevalent in green tea, unfermented, dried and unroasted cocoa beans [24] and chocolate [25]. Flavonols are also 
Citation: Song M, Olmstead JW, Rouseff RL, Tomasino E (2016) Investigation on the Profile of Phenolic Acids and Flavonoids with Antioxidant Capacity in Florida Highbush (Vaccinium corymbosum L.) and Rabbiteye (Vaccinium virgatum) Blueberries. J Exp Food Chem 2: 105. doi:10.4172/2472-0542.1000105

Page 2 of 9

present in a wide variety of fruits and vegetables $[5,26]$. The profile of the nonvolatile compounds with antioxidant capacity (phenolic acids, flavonoids) in blueberries at different locations had been reported. These locations include Chatsworth, New Jersey, USA [27], Georgia, USA [10], Spain [28] and near Olsztyn, Poland [29]. However, the profile of these compounds in highbush and rabbiteye blueberries, two major species in Florida, is limited [10]. Vaccinium corymbosum L.highbush blueberry, is a species of blueberry native to Northeastern America, found along the Gulf Coast from South Georgia to East Texas and in California. Vaccinium virgatum (commonly known as either rabbiteye blueberry or southern black blueberry) is a species of blueberry native to the Southeastern United States. The earliest ripening southern highbush cultivars reach maturity about 4 to 6 weeks earlier than the earliest rabbiteye cultivars grown at the same location. The ability to ripen blueberries earlier than other states in the U.S. ensures a higher price for these fruits. Specifically the market period from April 1 to May 10 is available almost exclusively to Florida growers and contribute to the year-round available of fresh market blueberries [30]. The aim of the study is to investigate the profile of phenolic compounds in Florida low-chill highbush and rabitteye blueberry cultivars, compare the differences in cultivars and subgroup them based on phenolic compositions. This information on Florida blueberry cultivars with low-chill and early ripening is important to help blueberry breeders and growers chose and/or grow those blueberries with the desired phenolic compositions.

\section{Materials and Methods}

\section{Standards}

The following external standards were obtained from Sigma Chemical Co. (St. Louis, MO): gallic acid, caffeic acid, ferulic acid, chlorogenic acid, protocatechuic acid and Kaempferol, quercetin, myricetin, quercetin-3-glucoside, quercetin-3-galactoside, and quercetin-3-o- $\alpha$-L-arabinoside, $(+)$ catechin and (-) epicatechin. All organic solvents used were of HPLC grade. Methanol, acetone, ethyl acetate and acetonitrile were purchased from Fisher Chemical (Fair Lawn, NJ); formic acid was bought from Fluka; all water was deionized and then distilled.

All standards were prepared as stock solutions in methanol and stored in darkness at $-18 \pm 2^{\circ} \mathrm{C}$. The concentrations for each stock standard are as follows; $2.45 \mathrm{mg} / \mathrm{ml}$ chlorogenic acid, $2.25 \mathrm{mg} / \mathrm{ml}$ caffeic acid, $2.02 \mathrm{mg} / \mathrm{ml}$ protocatechuic acid, $2.45 \mathrm{mg} / \mathrm{ml}$ ferulic acid, $3.66 \mathrm{mg} / \mathrm{ml}$ gallic acid, $3.7 \mathrm{mg} / \mathrm{ml} \mathrm{kaempferol,} 5.5 \mathrm{mg} / \mathrm{ml}$ quercetin dehydrate, $2.5 \mathrm{mg} / \mathrm{ml}$ myricetin, $0.1 \mathrm{mg} / \mathrm{ml}$ quercetin 3-galactoside, 0.1 $\mathrm{mg} / \mathrm{ml}$ quercetin 3-glucoside, $0.1 \mathrm{mg} / \mathrm{ml}$ quercetin 3-o- $\alpha-\mathrm{L}-$ arabinoside, $6.0 \mathrm{mg} / \mathrm{ml} \mathrm{(+)-catechin} \mathrm{hydrate} \mathrm{and} 5.7 \mathrm{mg} / \mathrm{ml} \mathrm{(-)-}$ epicatechin. Each day working solutions were prepared by $100 \times$ dilution with initial HPLC gradient solvent.

\section{Samples}

The highbush and rabbiteye blueberry samples were harvested ripe (the color of the berry skin should be from blue to dark blue) from University of Florida grower-cooperator farm near Gainesville, FL (29_470 3200 N, 82_070 2200 W). Harvest date was on May 2012 for highbush blueberries and May 22012 for rabbiteye blueberries. Approximately 200 gram samples (fresh weight) were randomly collected and quickly stored in freezer $\left(-18 \pm 2^{\circ} \mathrm{C}\right)$ using dry ice. Samples were transferred to Lake Alfred citrus and research education center (700 Experiment Station Rd. Lake Alfred, FL 33850) on dry ice.

\section{Extraction and analysis of phenolic acids, flavan-3-ol and flavonols}

Extraction procedure was carried out using mixed solvents: a combination of methanol (40\%), acetone $(40 \%)$ water $(20 \%)$ and formic acid (0.1\%). Sub samples of the frozen berries $(4.0 \pm 0.2 \mathrm{~g})$ were thawed and placed into a $100 \mathrm{~mL}$ stainless centrifuge tube and $24 \mathrm{ml}$ of the mixed solvents was added.

Samples were homogenized in a Lourdes homogenizer (Vernitron Medical Products, Carlstadt, N.J.) for $1.5 \mathrm{~min}$ and sonicated (Fisher Scientific FS-9 Ultrasonic Cleaner) at room temperature in the dark for $20 \mathrm{~min}$. Sonicated samples were then transferred into a clean $50 \mathrm{ml}$ centrifuge tube (Fisher Scientific) and centrifuged at $4380 \mathrm{rpm}$ for 10 $\min$.

The clear supernatant was collected and concentrated using a rotary evaporator at $35^{\circ} \mathrm{C}$ water bath under $70 \mathrm{cmHg}$ vacuums. It was further purified using a C-18 SPE cartridge (Phenomenex Strata C18-E 1000 $\mathrm{mg} / 6 \mathrm{ml}, 18.0 \%$ carbon loading, $500 \mathrm{~m}^{2} / \mathrm{g}$ surface area, $70^{\circ}$ A pore size, $55 \mu \mathrm{m}$ particle size). The concentrated sample was placed on the top of a $6 \mathrm{ml}$ column (preconditioned with $10 \mathrm{ml}$ of methanol followed by $10 \mathrm{ml}$ acidified water ( $3 \%$ formic acid)). A vacuum was used to pull the sample slowly through the cartridge (approximately one drop/min). The absorbed compounds on the column were first washed with $10 \mathrm{ml}$ distilled water, and then slowly eluted with $8 \mathrm{ml}$ of ethyl acetate. The eluent was collected into a $20-\mathrm{ml}$ glass vial and blown to dryness under pure nitrogen. The resulting residue was re-dissolved in $1.0 \mathrm{ml}$ methanol, clarified with a $0.45 \mu \mathrm{m}$ filter and placed in an amber $4-\mathrm{ml}$ vial (Fisher Scientific) prior to injection.

\section{HPLC conditions}

A Thermo Finnigan Surveyor HPLC system (Waltham, Mass., U.S.A.) coupled with a Phenomenex C-18 column (synergi, $250 \times 4.6$ $\mathrm{mm}, 4 \mu)$ and a supelguard LC-18 guard column, $20 \times 4.0 \mathrm{~mm}$ (Supelco, Bellefonte, PA) was used to analyze the phenolics. Column effluent was monitored on a photo diode array, PDA detector. Absorbance spectra between 200 and $600 \mathrm{~nm}$ were recorded for all peaks. Maximum wavelength $279 \mathrm{~nm}$ for flavan-3-ols, $360 \mathrm{~nm}$ for flavonols and 260-330 $\mathrm{nm}$ for phenolic acids was used.

Gradient elution was employed with a mobile phase according to Schwarz et al. (2003) [31] and consisted of $87 \%$ water, $3 \%$ acetonitrile, $10 \%$ formic acid (solvent A) and $40 \%$ water, $50 \%$ acetonitrile, $10 \%$ formic acid (solvent B). Elution details were as follows: 0-15 min, linear gradient from $85 \% \mathrm{~A} / 15 \%$ B to $57 \% \mathrm{~A} / 43 \% \mathrm{~B}$ at flow rate of 0.5 $\mathrm{ml} / \mathrm{min}$; $15-45 \mathrm{~min}$, linear gradient from $57 \% \mathrm{~A} / 43 \% \mathrm{~B}$ to $20 \% \mathrm{~A} / 80 \%$ $\mathrm{B}$ at flow rate of $0.5 \mathrm{ml} / \mathrm{min}$. The column was equilibrated for at least $15 \mathrm{~min}$ before the next sample was injected at flow rate of $1 \mathrm{ml} / \mathrm{min}$. 15 $\mu \mathrm{l}$ of each extracted sample was injected into the column using Thermo Finnigan autosampler. HPLC chromatograms were analyzed using Xcalibur software (Thermo Electron Corp., Waltham, Mass., U.S.A.).

\section{Identification of phenolic acids, flavan-3-ol and flavonols}

Two different methods were used in combination for the identification of HPLC peaks in the blueberry samples according to $\mathrm{Xu}$ and Chang [32]. The first method used external standards and identified peaks by comparing retention time and UV spectrum of each standard to the produced chromatogram [33]. The second method utilized internal standards, using the standard addition method [32]. The increase of peak areas at each retention time and 
Citation: Song M, Olmstead JW, Rouseff RL, Tomasino E (2016) Investigation on the Profile of Phenolic Acids and Flavonoids with Antioxidant Capacity in Florida Highbush (Vaccinium corymbosum L.) and Rabbiteye (Vaccinium virgatum) Blueberries. J Exp Food Chem 2: 105. doi:10.4172/2472-0542.1000105

Page 3 of 9

comparison of UV spectrum resulted in a second validation for each compound measured.

\section{Quantification of phenolic acids, flavan-3-ol and flavonols}

All identified phenolics were quantified with external standards using the same HPLC gradients as previously described. The stock solution of each standard was diluted into six series of working solutions with the initial composition of HPLC gradient solvent. Sixpoint calibration plots were constructed using peak areas obtained by adding known amounts of standards to initial HPLC gradient solvent and used to calculate the concentrations of compounds in each blueberry cultivar. Each point on the calibration curve was performed in triplicate. Compounds concentrations were expressed as micrograms per gram $(\mu \mathrm{g} / \mathrm{g})$ on a fresh weight basis.

\section{Data analyses}

Differences in individual phenolic compounds between the blueberry cultivars were evaluated using one-way analysis of variance (ANOVA) with Tukey HSD. All analyses were performed with IBM SPSS statistics 20.0 for Windows (SPSS Inc., Chicago, IL). Principle component analysis (PCA) and complete-linkage clustering analysis was performed using Unscrambler software (version 10.0.1 (CAMO ASA, Oslo, Norway). Variables were mean-centered and scaled for PCA and clustering analysis.

\section{Results and Discussion}

\section{Separation and identification of blueberry phenolic acids, flavan-3-ol and flavonols}

Twenty highbush blueberry cultivars including Sapphire, Windsor, Star, Bobolink, Primadonna, Springwide, Abundance, Southern Belle, Meadowlark, Emerald, Snow chaser, Springhigh, Raven, Southmoon, Sweetcrisp, Scintilla, Jewel, Farthing, Flicker and Rebel; and two rabitteye cultivars, Savory and Climax were selected in this study. Five phenolic acids, gallic acid, protocatechuic acid, chlorogenic acid, caffeic acid, ferulic acid; two flavan-3-ols including catechin and epicatechin; and five flavonols, quercetin-3-galactoside or quercetin-3glucoside,quercetin-3-arabinoside, myricetin, quercetin and kaempferol were identified and quantified. Retention time and wavelength of these compounds is shown in (Table 1). All of the compounds investigated had HPLC good resolution, except quercetin-3-galactoside and quercetin-3-glucoside. These were difficult to identify as they both eluted at the same retention time and had very similar spectra. The spectra of chlorogenic acid and quercetin-3galactoside, quercetin-3-glucoside standards were compared with the spectra of blueberry extracts, 'Emerald' and 'Southern Belle' (Figure 1). The spectrum of chlorogenic acid in 'Emerald' extract was perfectly lined up with the one in standard (Figure $1 \mathrm{~A}$ ). The identification of the compound responsible for the spectrum in (Figure $1 \mathrm{~B}$ ) was difficult as both quercetin-3-galactoside and quercetin-3-glucoside coeluted under current method conditions and had essentially identical UV spectra. The elution parameters need to be investigated further for separation of these two compounds.

\begin{tabular}{|l|l|l|}
\hline RT & $\lambda \max (\mathbf{n m})$ & Compounds \\
\hline 5.84 & 271 & gallic acid \\
\hline
\end{tabular}

\begin{tabular}{|l|l|l|}
\hline 8.78 & 295 & protocatechuic acid \\
\hline 9.54 & 279 & catechin \\
\hline 10.18 & 295,326 & chlorogenic acid \\
\hline 11.41 & 279 & epicatechin \\
\hline 13.07 & 298,323 & caffeic acid \\
\hline 19.17 & 353 & quercetin-3-galactoside or glucoside \\
\hline 21.3 & 295,322 & ferulic acid \\
\hline 21.47 & 357 & quercetin-3-arabinoside \\
\hline 24.21 & 370 & myricetin \\
\hline 31.41 & 370 & quercetin \\
\hline 42.05 & 366 & Kaempferol \\
\hline
\end{tabular}

Table 1: Primary phenolics identified in Florida blueberries.

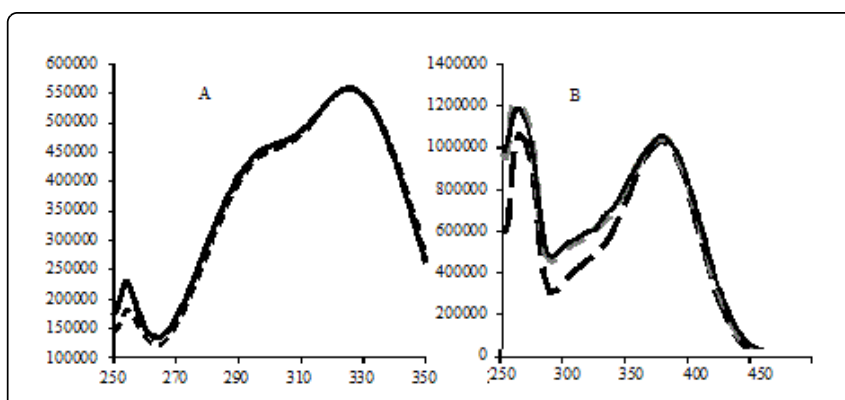

Figure 1: The spectrum of phenolic identified in blueberry cultivars compared with the standard. (A) Chlorogenic acid standard is the solid line; chlorogenic acid in blueberry cultivar 'Emerald' is the dashed line. (B) Quercetin-3-galactoside standard is represented by the solid line; quercetin-3-glucoside standard is the dotted line with grey color; the dashed line represents the spectrum of quercetin-3glucoside or quercetin-3-galactoside of blueberry cultivar 'Southern Belle' extracts.

The detailed phenolic composition of each cultivar is shown in Table 2 and Table 3. A pie chart was used to demonstrate the phenolic distribution of one cultivar, 'Meadowlark'. 'Meadowlark' was selected as it was the only cultivar that contained ferulic acid of the high-bush blueberries (Figure 2) and clearly displayed the phenolic complexity of blueberries. In total, flavonol aglycons accounted for more than half of the phenolics consisted of quercetin-3-galactoside or glucoside and quercetin-3-arabinoside; and phenolic acids comprised about $36 \%$ of the total phenolics, followed by flavan-3-ol (catechin); smaller portion of quercetin and kaempferol are quantified; myricetin and epicatechin were not detected. In terms of phenolic acid, simple phenolic acids comprised of ferulic acid, caffeic acid and gallic acid were accounted for 15\%; complex phenolic acids which were chlorogenic acid and protocatechuic acid accounted for around $21 \%$. Chlorogenic acid was the major phenolic acid, accounted for $18 \%$ of total phenolics. 
Citation: Song M, Olmstead JW, Rouseff RL, Tomasino E (2016) Investigation on the Profile of Phenolic Acids and Flavonoids with Antioxidant Capacity in Florida Highbush (Vaccinium corymbosum L.) and Rabbiteye (Vaccinium virgatum) Blueberries. J Exp Food Chem 2: 105. doi:10.4172/2472-0542.1000105

Page 4 of 9

\begin{tabular}{|c|c|c|c|c|c|c|c|c|c|c|c|}
\hline Cultivars & Catechin & $\begin{array}{l}\text { Epicatechi } \\
\mathrm{n}\end{array}$ & $\begin{array}{l}\text { Sum of } \\
\text { flavan- } \\
\text { 3-ol }\end{array}$ & $\begin{array}{l}\text { Quercetin-3 } \\
- \\
\text { galactoside } \\
\text { \&glucoside }\end{array}$ & $\begin{array}{l}\text { Quercetin-3- } \\
\text { arabinoside }\end{array}$ & Myricetin & Quercetin & Kaempferol & $\begin{array}{l}\text { Sum of } \\
\text { flavonols }\end{array}$ & $\begin{array}{l}\text { Total } \\
\text { phenolics }\end{array}$ & Subgroup \\
\hline Raven & 0.0 & 0.0 & 0.0 & $7.6 \pm 1.3$ & $10.6 \pm 1.4$ & $0.6 \pm 0.1$ & $0.6 \pm 0.0$ & $0.3 \pm 0.0$ & 19.6 & 29.5 & 1 \\
\hline Abundance & 0.0 & 0.0 & 0.0 & $19.3 \pm 1.2$ & $15.2 \pm 1.3$ & 0.0 & $0.9 \pm 0.1$ & $0.2 \pm 0.0$ & 35.6 & 48.9 & 1 \\
\hline Southmoon & 0.0 & 0.0 & 0.0 & $11.4 \pm 1.0$ & $10.3 \pm 0.5$ & $1.5 \pm 0.2$ & $0.4 \pm 0.0$ & $0.3 \pm 0.0$ & 23.9 & 49.1 & 1 \\
\hline Rebel & 0.0 & 0.0 & 0.0 & $26.1 \pm 2.0$ & $6.7 \pm 1.4$ & 0.0 & $0.2 \pm 0.0$ & $0.2 \pm 0.0$ & 33.2 & 50.9 & 1 \\
\hline Meadowlark & $2.7 \pm 1.2$ & 0.0 & 2.7 & $18.0 \pm 1.3$ & $15.0 \pm 1.5$ & 0.0 & $0.8 \pm 0.1$ & $0.4 \pm 0.0$ & 34.1 & 57.6 & 1 \\
\hline Flicker & $1.4 \pm 0.7$ & $2.6 \pm 0.5$ & 4.0 & $15.3 \pm 0.8$ & $19.3 \pm 2.2$ & 0.0 & $0.3 \pm 0.0$ & $0.4 \pm 0.1$ & 35.3 & 59.3 & 1 \\
\hline Sweetcrisp & $6.0 \pm 3.9$ & 0.0 & 6.0 & $30.4 \pm 0.3$ & $6.9 \pm 0.1$ & $1.7 \pm 0.3$ & $0.4 \pm 0.0$ & $0.1 \pm 0.0$ & 39.6 & 64.2 & 1 \\
\hline Springhigh & 0.0 & 0.0 & 0.0 & $18.3 \pm 1.3$ & $7.6 \pm 1.7$ & $0.9 \pm 0.2$ & $0.4 \pm 0.1$ & $0.3 \pm 0.0$ & 27.5 & 71.7 & 1 \\
\hline Scintilla & 0.0 & 0.0 & 0.0 & $17.6 \pm 2.0$ & $27.2 \pm 1.9$ & $1.1 \pm 0.1$ & $0.5 \pm 0.0$ & $0.2 \pm 0.0$ & 46.6 & 79.7 & 1 \\
\hline Farthing & 0.0 & 0.0 & 0.0 & $13.3 \pm 3.2$ & $13.1 \pm 2.2$ & $3.4 \pm 1.2$ & $0.5 \pm 0.1$ & $0.2 \pm 0.0$ & 30.6 & 81.7 & 2 \\
\hline Primadonna & $0.1 \pm 0.2$ & $6.8 \pm 2.0$ & 6.9 & $24.7 \pm 1.2$ & $5.0 \pm 0.3$ & $1.8 \pm 0.6$ & $0.3 \pm 0.0$ & $0.2 \pm 0.0$ & 31.9 & 86.4 & 2 \\
\hline Jewel & 0.0 & 0.0 & 0.0 & $36.0 \pm 1.1$ & $15.7 \pm 1.2$ & $2.6 \pm 1.0$ & $0.3 \pm 0.1$ & $0.2 \pm 0.0$ & 54.8 & 102.1 & 2 \\
\hline Snow chaser & 0.0 & 0.0 & 0.0 & $8.1 \pm 0.9$ & $36.3 \pm 1.2$ & 0.0 & $0.8 \pm 0.1$ & $0.2 \pm 0.0$ & 45.3 & 125.1 & 2 \\
\hline $\begin{array}{l}\text { Southern } \\
\text { Belle }\end{array}$ & 0.0 & $3.0 \pm 0.8$ & 3.0 & $44.9 \pm 3.2$ & $10.4 \pm 1.8$ & 0.0 & $0.8 \pm 0.1$ & $0.2 \pm 0.0$ & 56.2 & 139.8 & 2 \\
\hline Bobolink & $1.5 \pm 0.6$ & $9.9 \pm 1.8$ & 11.4 & $27.7 \pm 2.4$ & $17.6 \pm 5.8$ & $1.4 \pm 0.3$ & $0.5 \pm 0.1$ & $0.2 \pm 0.0$ & 47.4 & 145.7 & 2 \\
\hline Climax & $0.6 \pm 0.7$ & $9.5 \pm 5.6$ & 5.3 & $1.1 \pm 0.1$ & $13.5 \pm 0.9$ & 0 & $0.2 \pm 0.0$ & $0.1 \pm 0.0$ & 14.9 & 149.4 & 3 \\
\hline Springwide & 0.0 & $10.0 \pm 0.6$ & 10.0 & $31.9 \pm 2.8$ & $5.5 \pm 1.6$ & $2.5 \pm 0.1$ & $0.4 \pm 0.1$ & $0.1 \pm 0.0$ & 40.4 & 151.3 & 3 \\
\hline Windsor & $4.9 \pm 2.2$ & $13.6 \pm 2.6$ & 18.5 & $16.4 \pm 1.0$ & $13.8 \pm 1.5$ & $3.1 \pm 0.8$ & $0.2 \pm 0.0$ & $0.2 \pm 0.0$ & 33.7 & 165.9 & 3 \\
\hline Star & $1.9 \pm 0.2$ & $14.2 \pm 2.3$ & 16.1 & $38.0 \pm 5.0$ & $5.0 \pm 0.1$ & $3.4 \pm 0.8$ & $0.2 \pm 0.0$ & $0.2 \pm 0.0$ & 46.8 & 166.4 & 3 \\
\hline Savory & 0.0 & 0.0 & 0.0 & $4.5 \pm 1.2$ & $2.8 \pm 0.4$ & 0.0 & $0.2 \pm 0.0$ & $0.1 \pm 0.0$ & 7.6 & 209.8 & 3 \\
\hline sapphire & $23.9 \pm 4.4$ & $23.1 \pm 1.0$ & 47.0 & $12.4 \pm 0.4$ & $28.7 \pm 2.2$ & $1.5 \pm 0.2$ & $0.2 \pm 0.0$ & $0.1 \pm 0.0$ & 42.7 & 253.8 & 3 \\
\hline Emerald & 0.0 & 0.0 & 0.0 & $14.1 \pm 4.1$ & $39.0 \pm 8.6$ & 0.0 & $1.0 \pm 0.2$ & 0.0 & 54.1 & 262.5 & 3 \\
\hline
\end{tabular}

Table 3: Flavonoids and total phenolics concentration $(\mu \mathrm{g} / \mathrm{g})$ of 22 blueberry cultivars extracted with methanol/acetone/water/formic acid $(40 / 40 / 20 / 0.1)$. 
Citation: Song M, Olmstead JW, Rouseff RL, Tomasino E (2016) Investigation on the Profile of Phenolic Acids and Flavonoids with Antioxidant Capacity in Florida Highbush (Vaccinium corymbosum L.) and Rabbiteye (Vaccinium virgatum) Blueberries. J Exp Food Chem 2: 105. doi:10.4172/2472-0542.1000105

Page 5 of 9

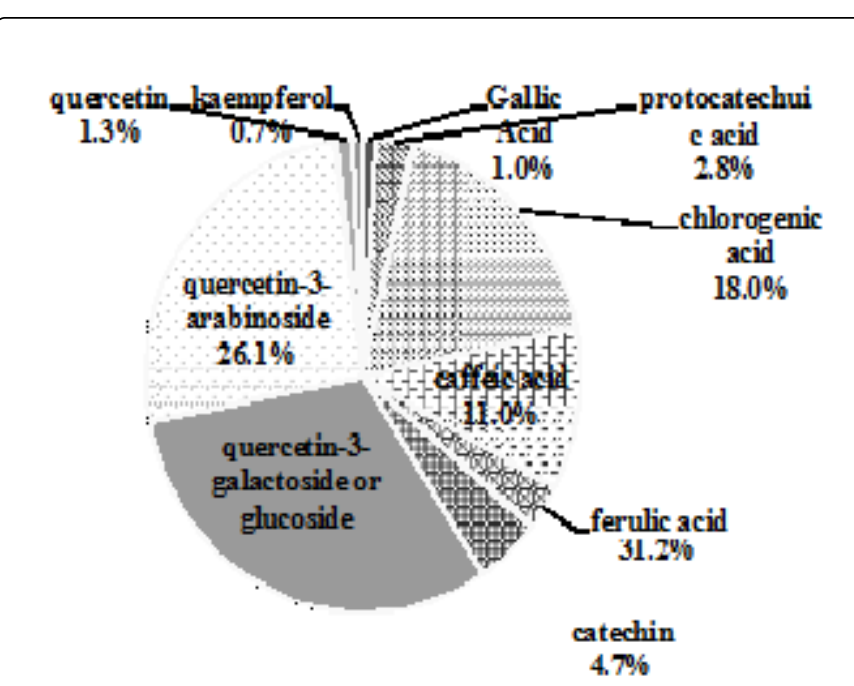

Figure 2: Distribution of phenolic acids and flavonoids from 'meadowlark' cultivar.

Identification of phenolic acids and flavonoids has been widely reported [10,1 27,29,34,35]. The high amount of chlorogenic acid in highbush blueberries found in our work is in agreement with the results found by Kader et al. (1996) [35] and Cho et al. (2004) [36]. They showed that of all phenolic acids, chlorogenic acid was the most dominant. However, using GC, Zadernowski et al. (2005) [29] reported that p-courmaric acid, not chlorogenic acid, was the main phenolic acid in European blueberries (Vaccinium myrtillus) from trimethylsilyl derivatives of phenolic acids. This difference $s$ is most likely due to type of analysis used. Of the flavonoids studied, kaempferol and myricetin were not reported in four highbush blueberrycultivars grown in Chatsworth NJ, in 1983 [27]. Other studies also reported undetectable levels of kaempferol or myricetin in blueberry cultivars from other geographic areas $[5,37,38]$. These compositional differences in blueberries from other areas in comparison to Florida would need to be verified with newer analytical instrumentation. More modern analytical equipment may now be sensitive enough to detect both kaempferol and myricetin in these berries as they were only detected in trace amounts detected in our study.

Sellappan et al. (2002) [10] quantified gallic acid, p-hydroxybenzoic acid, caffeic acid, ferulic acid, ellagic acid and the flavonoids of catechin, epicatechin, myricetin, quercetin, and kaempferol in 12 rabbiteye blueberry (Vaccinium ashei) cultivars and 5 southern highbush blueberry (Vaccinium corymbosum L. Hybrids) cultivars in Georgia harvested in June. They used the same species as in this study but different cultivars; interestingly chlorogenic acid and protocatechuic acid which was found abundantly in our research were not detected. Chlorogenic acid (a caffeic acid ester linked to quinic acid) and protocatechuic acid (precursor of gallic acid) are derived from phenylalanine via the shikimic acid pathway, belonged to different groups of phenolic acids, the hydroxycinnamic acid and hydroxybenzoic acids $[39,40]$. The absence of these two acids could be attributed to the hydrolysis or secondary metabolism to simple phenolic acids, or may be an effect of cultivar differences or the place where the berries were grown.Although the two phenolic acids were present in our result, the concentrations of other phenolic compounds found were much lower than in Sellappan et al. (2002) study.

\section{Effect of blueberry cultivars on the profile of phenolic acids, flavan-3-ol and flavonols}

Florida blueberry flavonoid and phenolic acid composition were profoundly different and these differences have not been previously reported (Table 3 and Figure 3). Generally, the blueberry cultivars can be divided into three groups based on the sum of all the phenolics (Table 3). The first group includes 'Raven', 'Abundance', 'Southmoon', 'Rebel,' 'Meadowlark', 'Flicker,' 'Sweetcrisp', 'Springhigh', and 'Scintilla'. These had the least amount of phenolics ranging from 29.5-79.7 $\mu \mathrm{g} / \mathrm{g}$ fresh fruit. The second group included 'Farthing', 'Primadonna', Jewel', 'Snow chaser', 'Southern Belle' and 'Bobolink'. Phenolics ranged from 81.7-145.7 $\mu \mathrm{g} / \mathrm{g}$ of total phenolics. 'Climax', 'Springwide,' 'Windsor', 'Star,' 'Savory', 'Sapphire' and 'Emerald' comprised the third group and contained the highest amounts of phenolics, 149.4-262.5 $\mu \mathrm{g} / \mathrm{g}$. Rabbiteye blueberries, 'Climax' and 'Savory' had the largest amount of phenolic acids, but smaller portion of flavonols.

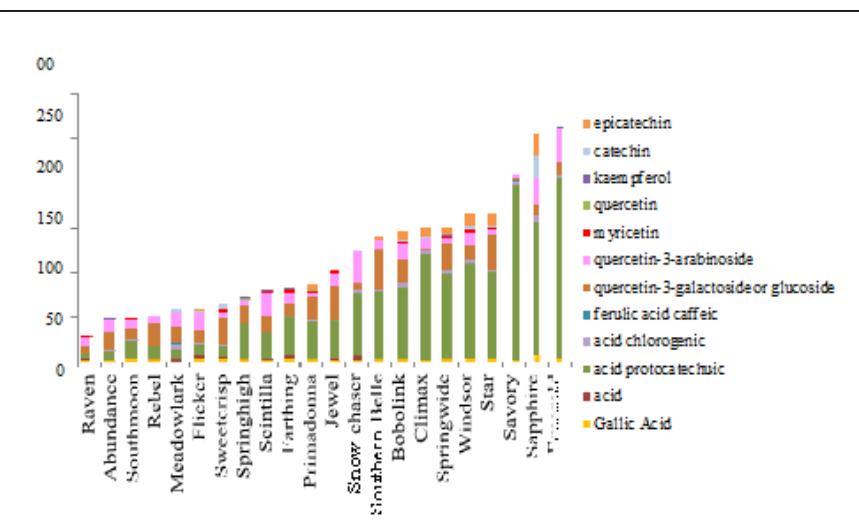

Figure 3: Relative distributions of concentration of phenolic acids and flavonoids in 22 blueberry cultivars.

The difference in phenolic acids and flavonols profiles between the blueberries may be related to a number of factors. Phenolic content is affected by pre-harvest environmental conditions, such as light and temperature, maturity at harvest and genetic differences [41-43]. The berries in our study did not go through any postharvest storage or processing, other factors that can alter phenolic acid content [44]. The variation of phenolic acids in the different cultivars are most likely due to genetic and maturity differences. Castrejón et al. [11] showed that flavonoid biosythesis is linked to developmental stage. Specifically differences may be linked to enzymatic activity at different developmental stages. Both phenolic acid and flavanol synthesis rely on enzymatic schemes. Phenolic acids are from the shikimic acid pathway and flavonols are from the phenolpropanoid pathway [45]. The low flavanol content noted in 'Climax' and 'Savory" may be related to maturity as these compounds typically decrease as berries ripen [11]. This suggests that these two cultivars were more mature than the other blueberries in the study. Phenolic acids accounted for the major percentage of the total phenolics by weight and most likely made a strong contribution to the differences of the profile of cultivars. Interestingly, the cultivars could also be separated into three similar groups from the least amount to the greatest by weight (Table 2), 10 cultivars in the first group, 'Raven', 'Abundance, 'Rebel,' 'Sweetcrisp', 'Flicker,' 'Meadowlark', 'Southmoon', 'Scintilla, 'Springhigh' and 'Jewel'; 7 cultivars in the second group, 'Primadonna, 'Farthing, 'Snow chaser, 'Southern Belle', 'Bobolink', 'Springwide' and 'Star'; 5 cultivars in the 
Citation: Song M, Olmstead JW, Rouseff RL, Tomasino E (2016) Investigation on the Profile of Phenolic Acids and Flavonoids with Antioxidant Capacity in Florida Highbush (Vaccinium corymbosum L.) and Rabbiteye (Vaccinium virgatum) Blueberries. J Exp Food Chem 2: 105. doi:10.4172/2472-0542.1000105

Page 6 of 9

third group, 'Windsor,' 'Climax,' 'Sapphire, 'Savory' and 'Emerald'. This was a slightly different subgrouping than that obtained from the sum of phenolics. 'Jewel' was grouped into the first subgroup instead of the second one; 'Springwide' and 'Star' were moved to the second subgroup based on phenolic acids.

\begin{tabular}{|c|c|c|c|c|c|c|c|}
\hline Cultivars & Gallic Acid & Protocatechuic acid & Chlorogenic acid & Caffeic acid & Ferulic acid & Sum of phenolic & Subgroup \\
\hline Raven & $1.6 \pm 0.3$ & $1.8 \pm 0.5$ & $5.6 \pm 1.7$ & $0.9 \pm 0.1$ & 0 & 9.8 & 1 \\
\hline Abundance & $0.7 \pm 0.0$ & 0 & $11.6 \pm 0.4$ & $1.0 \pm 0.2$ & 0 & 13.3 & 1 \\
\hline Rebel & $2.2 \pm 0.3$ & $1.5 \pm 0.3$ & $13.0 \pm 8.6$ & $1.0 \pm 0.0$ & 0 & 17.7 & 1 \\
\hline Sweetcrisp & $2.9 \pm 0.0$ & $1.4 \pm 0.2$ & $12.7 \pm 0.1$ & $1.5 \pm 0.0$ & 0 & 18.6 & 1 \\
\hline Flicker & $3.8 \pm 0.2$ & $4.0 \pm 0.2$ & $10.8 \pm 1.0$ & $1.5 \pm 0.2$ & 0 & 20 & 1 \\
\hline Meadowlark & $0.6 \pm 0.1$ & $1.6 \pm 0.2$ & $10.4 \pm 2.6$ & $6.3 \pm 1.1$ & $1.9 \pm 0.2$ & 20.7 & 1 \\
\hline Southmoon & $1.8 \pm 0.1$ & $0.8 \pm 0.3$ & $21.7 \pm 1.5$ & $0.9 \pm 0.1$ & 0 & 25.2 & 1 \\
\hline Scintilla & $1.2 \pm 0.1$ & $0.9 \pm 0.2$ & $29.7 \pm 0.3$ & $1.4 \pm 0.2$ & 0 & 33.1 & 1 \\
\hline Springhigh & $1.8 \pm 0.4$ & $1.2 \pm 0.2$ & $39.4 \pm 4.5$ & $1.9 \pm 0.2$ & 0 & 44.2 & 1 \\
\hline Jewel & $0.9 \pm 0.2$ & $2.0 \pm 0.6$ & $43.1 \pm 4.4$ & $1.3 \pm 0.3$ & 0 & 47.3 & 1 \\
\hline Primadonna & $2.4 \pm 0.2$ & 0 & $42.5 \pm 5.0$ & $2.7 \pm 0.5$ & 0 & 47.5 & 2 \\
\hline Farthing & $1.6 \pm 0.2$ & $3.9 \pm 0.9$ & $44.2 \pm 0.6$ & $1.4 \pm 0.2$ & 0 & 51.2 & 2 \\
\hline Snow chaser & $1.5 \pm 0.3$ & $4.1 \pm 1.6$ & $71.2 \pm 0.9$ & $3.0 \pm 0.3$ & 0 & 79.8 & 2 \\
\hline Southern Belle & $2.1 \pm 0.8$ & 0 & $76.9 \pm 0.5$ & $1.7 \pm 0.3$ & 0 & 80.7 & 2 \\
\hline Bobolink & $2.4 \pm 0.3$ & 0 & $79.8 \pm 18.4$ & $4.6 \pm 0.8$ & 0 & 86.9 & 2 \\
\hline Springwide & $2.2 \pm 0.1$ & 0 & $96.4 \pm 6.8$ & $2.3 \pm 0.2$ & 0 & 100.9 & 2 \\
\hline Star & $3.0 \pm 0.9$ & 0 & $96.9 \pm 9.9$ & $3.5 \pm 0.6$ & 0 & 103.5 & 2 \\
\hline Windsor & $3.5 \pm 0.2$ & 0 & $106.6 \pm 5.8$ & $3.6 \pm 0.6$ & 0 & 113.7 & 3 \\
\hline Climax & $1.1 \pm 0.0$ & 0 & $119.7 \pm 41.1$ & $3.4 \pm 0.6$ & $0.3 \pm 0.1$ & 124.4 & 3 \\
\hline sapphire & $6.3 \pm 1.4$ & 0 & $149.5 \pm 23.7$ & $8.2 \pm 3.8$ & 0 & 164 & 3 \\
\hline Savory & $0.8 \pm 0.2$ & 0 & $196.3 \pm 39.9$ & $4.5 \pm 0.9$ & $0.6 \pm 0.1$ & 202.1 & 3 \\
\hline Emerald & $1.9 \pm 0.6$ & $1.8 \pm 0.7$ & $201.1 \pm 42.6$ & $3.4 \pm 1.1$ & 0 & 208.3 & 3 \\
\hline
\end{tabular}

Table 2: Phenolic aids concentration ( $\mu \mathrm{g} / \mathrm{g})$ of 22 blueberry cultivars extracted with methanol/acetone/water/formic acid (40/40/20/0.1).

The distribution of 22 blueberry cultivars based on each phenolic measured is shown using PCA (Figure 4) and complete-linkage clustering (Figure 5). Complete-linkage clustering was used to confirm the groupings found using PCA. The first two components of PCA explained $95 \%$ of the variation, with PC1 and PC2 contributing $80 \%$ and $15 \%$, respectively (Figure 4). There following 5 subgroups were found, 'Sweetcrisp' and 'Rebel' were all on the lower left quadrant of the PCA which contained more quercetin-3-galactoside or glucoside (subgroup 1); seven cultivars consisted of higher quercetin-3arabinoside and had high scores on negative PC1 (subgroup 2); seven cultivars (subgroup 3), and 'Snow chaser', 'Sapphire' and 'Windsor' (subgroup 4) rich in chlorogenic acid had low positive scores on PC1but separated more by PC2; while 'Emerald,' 'Climax' and 'Savory' had high scores on the right quadrant of the PCA (subgroup 5). 
Citation: Song M, Olmstead JW, Rouseff RL, Tomasino E (2016) Investigation on the Profile of Phenolic Acids and Flavonoids with Antioxidant Capacity in Florida Highbush (Vaccinium corymbosum L.) and Rabbiteye (Vaccinium virgatum) Blueberries. J Exp Food Chem 2: 105. doi:10.4172/2472-0542.1000105

Page 7 of 9

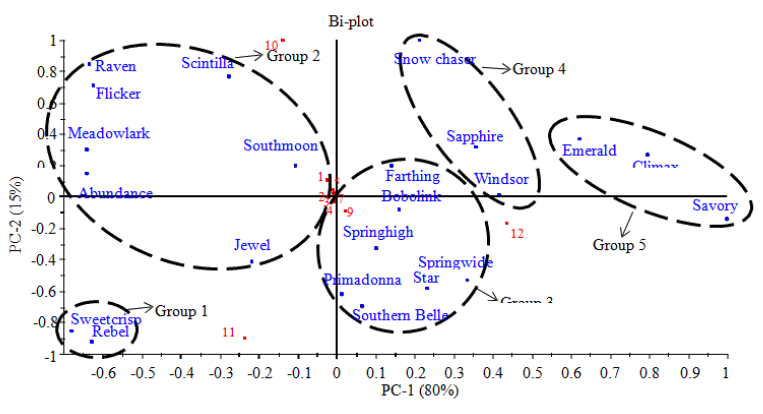

Figure 4: PCA bi-plot of 22 blueberry cultivars according to phenolic compositions. (1) protocatechuic acid, (2) kaempferol, (3) catechin, (4) myricetin, (5) caffeic acid, (6) quercetin, (7) ferulic acid, (8) gallic acid, (9) epicatechin, (10) quercetin-3-arabinoside, (11) quercetin-3-galactoside or glucoside, (12) chlorogenic acid.

PCA showed that the majority of the variation between the cultivars was due to variation in quercetin-3-galactoside or glucoside, quercetin-3-arabinoside and chlorogenic acid. The composition differences of these compounds in certain cultivars may reflect the importance of endogenous factors during the biosynthesis, such as activities of UDP-glycosyltransferase involved in glycosylation of flavonols [46] and caffeoyl-CoA in the formation of chlorogenic acid [47]. Evidence has also shown that genotype impacts phenolic composition [48], as does maturity [129]. Among the main phenolic compounds, the distribution of chlorogenic acid, and quercetin derivatives in 5 highbush blueberry (Vaccinium corymbosum L.) Juices were dependent on cultivar [48]. This founding was in agreement with our results showed in PCA.Reports in highbush blueberry planted in Berlin-Dahlem (Germany) showed that flavonols (mainly quercetin derivatives) and hydroxycinnamic acids (caffeic and chlorogenic acid) varied and decreased during ripening stage [11]. This maturity effect may also help to explain that the differences in phenolic composition of different cultivars were related to quercetin-3galactoside or glucoside, quercetin-3-arabinoside and chlorogenic acid in our study (Figure 4).

Dendrogram from clustering analysis also showed agreement with PCA groups. Five significantly different $(\mathrm{p}<0.05)$ distinct clusters were produced (Figure 5) $(\mathrm{p}<0.05)$ which correspond to the 5 clusters found from PCA. Cluster 1 and cluster 2 contained 9 cultivars; all of these cultivars except 'Jewel' had lower amount of phenolic acids and total phenolics. Clusters 4 and 5 contained 13 cultivars which had greater amounts of phenolic acids and total phenolics. Interestingly, the 22 blueberry cultivars were divided into the same number of subgroups using both complete-linkage clustering analysis and PCA. The distance between these groups were similar as well.

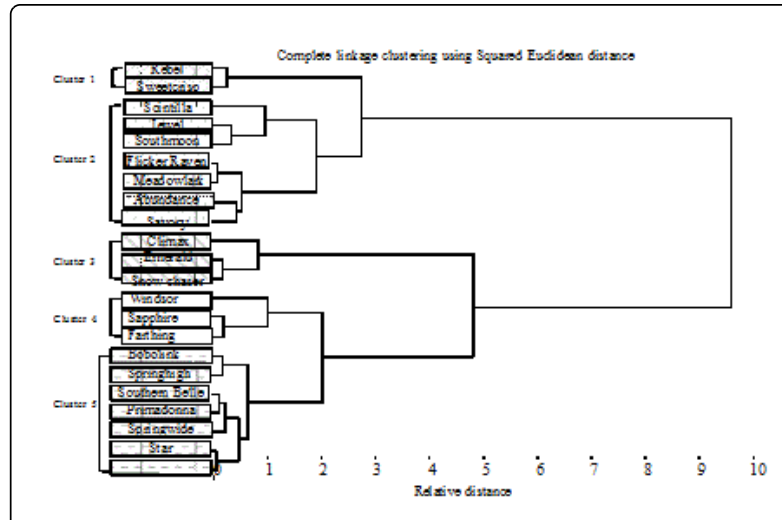

Figure 5: Dendrogram of 22 blueberry cultivars based on phenolic composition using Complete- linkage clustering analysis by Euclidean distance or its square for similarity relationships.

The groups found in PCA were very similar to those produced from clustering, although some small differences were noted. Groups 1 and 2 in PCA contained similar cultivars with cluster 1and 5. Group 3 from PCA corresponded to cluster 2. Cultivars in group 4 corresponded to cluster 4 and cultivars in group 5 from PCA corresponded with cluster 3. The slight differences may be explained by which each phenolic compound contribute different weight to the total phenolics profile (Figure 3). Additionally the clustering does provide more groupings than PCA should clustering move further down the dendrogram. A maximum of 13 different clusters can be found in the cluster dendrogram. The clusters that correspond with the PCA data occur at a relative distance of 2 . Therefore clustering analysis may provide more detailed information than PCA and in the future may be used over PCA.

This is the first report of the phenolic acid and flavonoid profiles of Florida blueberry cultivars. The cultivars clearly differed based on chemical composition resulting in five distinct subgroups. Beyond the phenolic acid and flavonoid information these profiles are important to blueberry growers and breeders looking to produce blueberries with target phenolic composition. Particularly since Florida blueberries dominate the fresh market for spring and early-summer blueberries. Additionally clustering analysis provides more detailed information on differences between blueberries in comparison to PCA.

\section{Acknowledgment}

Great thanks are given to John Smoot and Qiong Cheng (University of Florida, Citrus Research and Education Center, FL) for technical support.

\section{References}

1. Williamson J, Olmstead J, Lyrene P (2012) Florida's commercial blueberry industry.

2. Fang N, Yu S, Prior RL (2002) LC/MS/MS characterization of phenolic constituents in dried plums. J Agric Food Chem 50: 3579-3585.

3. Herrmann K (1976) Flavonols and flavones in food plants: a review. Int J Food Sci Tech 11: 433-448.

4. Jiang D, Peterson D (2010) Role of hydroxycinnamic acids in food flavor: a brief overview. Phytochem Rev 9: 187-193. 
Citation: Song M, Olmstead JW, Rouseff RL, Tomasino E (2016) Investigation on the Profile of Phenolic Acids and Flavonoids with Antioxidant Capacity in Florida Highbush (Vaccinium corymbosum L.) and Rabbiteye (Vaccinium virgatum) Blueberries. J Exp Food Chem 2: 105. doi:10.4172/2472-0542.1000105

Page 8 of 9

5. Häkkinen SH, Kärenlampi SO, Heinonen IM, Mykkänen HM, Törrönen AR (1999) Content of the flavonols quercetin, myricetin, and kaempferol in 25 edible berries. J Agric Food Chem 47: 2274-2279.

6. Heinonen IM, Meyer AS, Frankel EN (1998) Antioxidant Activity of Berry Phenolics on Human Low-Density Lipoprotein and Liposome Oxidation. J Agric Food Chem 46: 4107- 4112.

7. Kay CD, Holub BJ (2002) The effect of wild blueberry (Vaccinium angustifolium) consumption on postprandial serum antioxidant status in human subjects. Br J Nutr 88: 389-398.

8. Kähkönen MP Hopia AI, Heinonen M (2001) Berry phenolics and their antioxidant activity. J Agric Food Chem 49: 4076-4082.

9. Zheng W, Wang SY (2003) Oxygen radical absorbing capacity of phenolics in blueberries, cranberries, chokeberries, and lingonberries. J Agric Food Chem 51: 502-509.

10. Sellappan S, Akoh CC, Krewer G (2002) Phenolic compounds and antioxidant capacity of Georgia-grown blueberries and blackberries. J Agric Food Chem 50: 2432-2438.

11. Castrejón ADR, Eichholz I, Rohn S, Kroh LW, Huyskens-Keil S (2008) Phenolic profile and antioxidant activity of highbush blueberry (Vaccinium corymbosum L.) during fruit maturation and ripening. Food Chem 109: 564-572.

12. Wang SY, Chen H, Camp MJ, Ehlenfeldt MK (2012) Flavonoid constituents and their contribution to antioxidant activity in cultivars and hybrids of rabbiteye blueberry (Vaccinium ashei Reade). Food Chem 132: 855-864.

13. Huang WY, Zhang HC, Liu WX, Li CY (2012) Survey of antioxidant capacity and phenolic composition of blueberry, blackberry, and strawberry in Nanjing. J Zhejiang Univ Sci B 13: 94-102.

14. Mattila P, Hellström J, Törrönen R (2006) Phenolic acids in berries, fruits, and beverages. J Agric Food Chem 54: 7193-7199.

15. Núñez Sellés AJ, Vélez Castro HT, Agüero-Agüero J, González-González J, Naddeo F, et al. (2002) Isolation and Quantitative Analysis of Phenolic Antioxidants, Free Sugars, and Polyols from Mango (Mangifera indica L.) Stem Bark Aqueous Decoction Used in Cuba as a Nutritional Supplement. J Agric Food Chem 50: 762-766.

16. Peleg H, Naim M, Rouseff RL, Zehavi U (1991) Distribution of bound and free phenolic acids in oranges (Citrus sinensis) and Grapefruits (Citrus paradisi). J Sci Food Agric 57: 417- 426.

17. Schieber A Keller P, Carle R (2001) Determination of phenolic acids and flavonoids of apple and pear by high-performance liquid chromatography. J Chromatogr A 910: 265-273.

18. Luthria DL, Pastor-Corrales MA (2006) Phenolic acids content of fifteen dry edible bean (Phaseolus vulgaris L.) varieties. J Food Comp Anal 19: 205-211.

19. Barros L, Dueñas M, Ferreira IC, Baptista P, Santos-Buelga C (2009) Phenolic acids determination by HPLC-DAD-ESI/MS in sixteen different Portuguese wild mushrooms species. Food Chem Toxicol 47: 1076-1079.

20. Mattila P, Hellström J (2007) Phenolic acids in potatoes, vegetables, and some of their products. J Food Comp Anal 20: 152-160.

21. Huang CJ, Zayas JF (1991) Phenolic Acid Contributions to Taste Characteristics of Corn Germ Protein Flour Products. J Food Sci 56: 1308-1310.

22. Fallico B, Lanza MC, Maccarone E, Asmundo CN, Rapisarda P (1996) Role of Hydroxycinnamic Acids and Vinylphenols in the Flavor Alteration of Blood Orange Juices. J Agric Food Chem 44: 2654-2657.

23. Ghasemzadeh A, Ghasemzadeh N (2011) Flavonoids and phenolic acids: Role and biochemical activity in plants and human. J Med Plant Res 5: 6697-6703.

24. Taubert D Berkels R, Klaus W, Roesen R (2002) Nitric oxide formation and corresponding relaxation of porcine coronary arteries induced by plant phenols: essential structural features. J Cardiovasc Pharmacol 40: 701-713.

25. Kofink M, Papagiannopoulos M, Galensa R (2007) (-)-Catechin in cocoa and chocolate: occurrence and analysis of an atypical flavan-3-ol enantiomer. Molecules 12: 1274-1288.
26. Škerget M, Kotnik P, Hadolin M, Hraš AR, Simonic M, et al. (2005) Phenols, proanthocyanidins, flavones and flavonols in some plant materials and their antioxidant activities. Food Chem 89: 191-198.

27. Bilyk A, Sapers GM (1986) Varietal differences in the quercetin, kaempferol, and myricetin contents of highbush blueberry, cranberry, and thornless blackberry fruits. J Agric Food Chem 34: 585-588.

28. Faria A Oliveira J, Neves P, Gameiro P, Santos-Buelga C, et al. (2005) Antioxidant properties of prepared blueberry (Vaccinium myrtillus) extracts. J Agric Food Chem 53: 6896-6902.

29. Zadernowski R, Naczk M, Nesterowicz J (2005) Phenolic acid profiles in some small berries. J Agric Food Chem 53: 2118-2124.

30. Williamson JG, Lyrene PM (2009) Blueberry varieties for Florida.

31. Schwarz M, Hofmann G, Winterhalter P (2004) Investigations on anthocyanins in wines from Vitis vinifera $\mathrm{cv}$. pinotage: factors influencing the formation of pinotin A and its correlation with wine age. J Agric Food Chem 52: 498-504.

32. Xu B, Chang SKC (2009) Total Phenolic, Phenolic Acid, Anthocyanin, Flavan-3-ol, and Flavonol Profiles and Antioxidant Properties of Pinto and Black Beans (Phaseolus vulgaris L.) as Affected by Thermal Processing. J Agric Food Chem 57: 4754-4764.

33. Mattila P, Kumpulainen J (2002) Determination of free and total phenolic acids in plant-derived foods by HPLC with diode-array detection. J Agric Food Chem 50: 3660-3667.

34. Marshall DA, Stringer SJ, Spiers JD (2012) Stilbene, Ellagic Acid, Flavonol, and Phenolic Content of Muscadine Grape (Vitis rotundifolia Michx.) Cultivars Pharmaceutical Crops 3: 69-77.

35. Kader F, Rovel B, Girardin M, Metche M (1996) Fractionation and identification of the phenolic compounds of Highbush blueberries (Vaccinium corymbosum, L.). Food Chem 55: 35-40.

36. Cho MJ, Howard LR, Prior RL, Clark JR (2004) Flavonoid glycosides and antioxidant capacity of various blackberry, blueberry and red grape genotypes determined by high-performance liquid chromatography/mass spectrometry. J Sci Food Agric 84: 1771-1782.

37. Häkkinen SH, Törrönen AR (2000) Content of flavonols and selected phenolic acids in strawberries and Vaccinium species: influence of cultivar, cultivation site and technique. Food Res Int 33: 517-524.

38. Riihinen K, Jaakola L, Kärenlampi S, Hohtola A (2008) Organ-specific distribution of phenolic compounds in bilberry (Vaccinium myrtillus) and 'northblue' blueberry (Vaccinium corymbosum x V. angustifolium). Food Chem 110: 156-160.

39. Kakkar S, Bais S1 (2014) A review on protocatechuic Acid and its pharmacological potential. ISRN Pharmacol.

40. Heleno SA, Martins A, Queiroz MJ, Ferreira IC (2015) Bioactivity of phenolic acids: metabolites versus parent compounds: a review. Food Chem 173: 501-513.

41. Prior RL, Cao G, Martin A, Sofic E, McEwen J, et al. (1998) Antioxidant capacity as influenced by total phenolic and anthocyanin content, maturity, and variety of Vaccinium species. J Agric Food Chem 46: 2686-2693.

42. Connor AM, Luby JJ, Tong CB, Finn CE, Hancock JF (2002) Genotypic and environmental variation in antioxidant activity, total phenolic content, and anthocyanin content among blueberry cultivars. J Am Soc Hort Sci 127: 89-97.

43. Wang J, Kalt W, Sporns P (2000) Comparison between HPLC and MALDI-TOF MS analysis of anthocyanins in highbush blueberries. J Agric Food Chem 48: 3330-3335.

44. Kalt W, Forney CF, Martin A, Prior RL (1999) Antioxidant capacity, vitamin $\mathrm{C}$, phenolics, and anthocyanins after fresh storage of small fruits. J Agric Food Chem 47: 4638-4644.

45. Zifkin M, Jin A, Ozga JA, Zaharia LI, Schernthaner JP, et al. (2012) Gene expression and metabolite profiling of developing highbush blueberry fruit indicates transcriptional regulation of flavonoid metabolism and activation of abscisic acid metabolism. Plant Physiol 158: 200-224. 
Citation: Song M, Olmstead JW, Rouseff RL, Tomasino E (2016) Investigation on the Profile of Phenolic Acids and Flavonoids with Antioxidant Capacity in Florida Highbush (Vaccinium corymbosum L.) and Rabbiteye (Vaccinium virgatum) Blueberries. J Exp Food Chem 2: 105. doi:10.4172/2472-0542.1000105

Page 9 of 9

46. Czemmel S, Heppel SC, Bogs J (2012) R2R3 MYB transcription factors: key regulators of the flavonoid biosynthetic pathway in grapevine. Protoplasma 249: S109-118.

47. Stöckigt J, Zenk MH (1974) Enzymatic synthesis of chlorogenic acid from caffeoyl coenzyme A and quinic acid. FEBS Lett 42: 131-134.
48. Brambilla A Lo Scalzo R, Bertolo G, Torreggiani D (2008) Steamblanched highbush blueberry (Vaccinium corymbosum L.) juice: phenolic profile and antioxidant capacity in relation to cultivar selection. J Agric Food Chem 56: 2643-2648. 